\title{
Grecia de la dictadura a la democracia (1974-1986): ¿continuidad o ruptura?
}

\section{Greece from the dictatorship to democracy (1974-1986): continuity or rupture?}

\author{
SETHELOS ISIDOROS BALIOS \\ Universidad Complutense de Madrid \\ sethelos@windowslive.com
}

Resumen: Después del fracasado golpe de Estado en Chipre, los dirigentes militares de Grecia decidieron instaurar un gobierno civil para tratar la crisis que se había provocado. Así, el viejo político conservador Konstantinos Karamanlís regresó en julio de 1974, después de once años en el exilio, para formar gobierno. El presente artículo examina las características más significantes del nuevo sistema político de la Metapolitepsi y cómo estas supusieron la ruptura con el pasado. Concretamente, nos enfocaremos en la legalización del Partido Comunista, en la abolición de la Monarquía, en la nueva constitución y los poderes que otorgaba al presidente de la República, en el equilibrio de poder entre el primer ministro y el presidente de la República y, por último, la revisión constitucional de 1986.

Palabras clave: Transición, equilibrio de poder, presidente de la República, Monarquía, Partido Comunista.

\begin{abstract}
After the failed coup d'état in Cyprus, the leaders of the Greek military junta called for the formation of a civil government in order to deal with the crisis. The experienced conservative leader Konstantinos Karamanlis returned in July of 1974 after eleven years in exile to form a government. This article examines the most notable aspects of the new political system of the Metapolitefsi and how they marked the rupture with the past. We will focus on the legalization of the Communist Party, the abolishment of the monarchy, the new constitution of 1975 and the powers accredited to the President, the balance of power between the President and the Prime Minister and finally, on the constitutional revision of 1986 .
\end{abstract}

Keywords: Transition, balance of power, President of the Republic, monarchy, Communist Party.

Recibido: 21 de febrero de 2017; aceptado: 15 de agosto de 2017; publicado: 27 de marzo de 2018. Revista Historia Autónoma, 12 (2018), pp. 225-242.

e-ISSN: 2254-8726; DOI: https://doi.org/10.15366/rha2018.12.012. 
Introducción

El 21 de abril de 1967 fue establecida en Grecia la dictadura de los Coroneles. Según los golpistas su objetivo principal era la salvación del país de la "amenaza comunista". Siete años después y tras el fallido golpe de Estado en Chipre contra Makarios III en 1974 que fue seguido por la invasión del Ejército turco en la isla, los jefes de la Dictadura de los coroneles decidieron dejar el poder en manos de los políticos. Sin embargo, los distintos intereses dentro del régimen tuvieron sus efectos en la estabilidad del mismo ${ }^{2}$. Estos se hicieron más visibles durante la abolición de la monarquía y el intento de Georgios Papadopoulos de realizar una liberación del régimen en 1973, hecho que favoreció el desarrollo de movilizaciones estudiantiles $^{3}$ que con la crisis económica de 1973 también tuvieron efectos en su estabilidad ${ }^{4}$. La estimación del embajador estadounidense era que la posición del líder de golpe de 1967, Georgios Papadopoulos, estaba en cuestión ${ }^{5}$. Esto finalmente fue así, con lo que Papadopoulos fue sustituido por el brigadier Dimitrios Ioannidis pocos días después de la represión sangrienta de los estudiantes en la Escuela Politécnica en noviembre de 1973. Él, aunque no ocupó ningún cargo civil oficialmente, era el nuevo hombre fuerte del régimen hasta el colapso de la dictadura el 23 de julio de $1974^{6}$.

Acababa así un periodo de siete años para dar paso a una nueva etapa en la historia griega. Sin embargo, el objetivo fundamental de estos primeros años, conocido en el discurso público griego como Metapolitefsi, no fue solo superar la herencia de la dictadura, sino también dejar atrás toda la época posterior a la guerra civil (1946-1949) y la experiencia política desde dichos años hasta el golpe de Estado y la dictadura (1967-1974), una época afectada también por la realidad de un mundo bipolar. Por tanto, se trataba de dejar atrás tanto el sistema político de 1949-1967, como los siete años de Dictadura, pero de una forma en que pudiera ser controlada, es decir, sin crear nuevos desafíos en el proceso de transición democrática.

De esta manera, la detención de los responsables de la Dictadura, la legalización del Partido Comunista (KKE) y el referéndum sobre la monarquía cumplían con dicho objetivo de establecer un nuevo sistema político y fueron las acciones de los primeros gobiernos pos-

\footnotetext{
${ }^{1}$ Gómez Fernández, Ana Belén, "La llegada de la democracia al Mediterráneo: las transiciones de Portugal, Grecia y España", en Historia Actual Online, 25 (2011), p. 9.

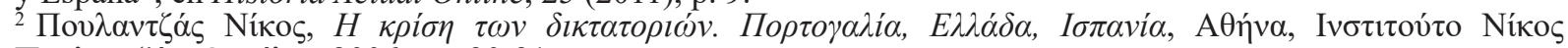

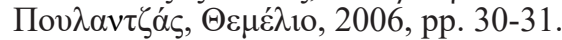

${ }^{3}$ Kornetis, Kostis, “UUn 68 periférico? Reflexiones sobre un análisis comparativo de la resistencia estudiantil en los regímenes autoritarios de la Grecia de los coroneles y de la España tardofranquista”, en Studia histórica. Historia Contemporánea, 21 (2003), p. 103.

${ }^{4}$ Alonso, Sonia y José María Maravall, "Democratizations in the European Periphery", en Estudio/Working Paper, 169 (2001), p. 13.

5 "Telegram from the Embassy in Greece to the Department of State, Athens, April 21, 1973". «https://history.state. gov/historicaldocuments/frus1969-76v30/d2» [consultado el 30 de noviembre de 2016].

${ }^{6}$ Contogeorgis, Georgios, "La dictadura militar en Grecia (1967-1974). ¿Cómo enfocar el fenómeno autoritario?”, en Studia histórica. Historia Contemporánea, 21 (2003), pp. 41-42.
} 
autoritarios las que marcaron la ruptura con el pasado inmediato. En primer lugar, la detención de los cabecillas del golpe del 21 de abril de 1967 y luego el juicio de los responsables de la represión de los sucesos en la Universidad Politécnica significaron que el nuevo sistema político no iba a aceptar la acción de los grupos militares o de extrema derecha que después de la guerra civil habían funcionado en repetidas ocasiones como forma de presión política y social no oficialmente reconocidas por el Estado como por ejemplo había ocurrido con el asesinato del diputado de izquierda Grigoris Lambrakis en 1963. A pesar de esto, no hubo una persecución masiva a quienes habían participado en la Dictadura porque el Tribunal Supremo decidió que el crimen de alta traición se cometió la noche del 21 de abril de 1967 y no a lo largo de los siete años?

En segundo lugar, la legalización del Partido Comunista marcó de forma clara y oficial el fin de una política de anticomunismo estatal que se sumaba a la división política y social existente de fuerzas "nacionales" y "antinacionales". En tercer y último lugar, la convocatoria de un referéndum el 8 de diciembre que preguntaba sobre Monarquía o República fue exitosa ya que tanto los partidos parlamentarios ${ }^{8}$, incluso el partido conservador siendo así una ruptura importante respecto a su pasado monárquico, a pesar de que algunos miembros del partido votaron por el Rey Konstantinos II aceptaron el resultado, cerrando de forma definitiva la cuestión entre Monarquía o República9 . De esta manera, tiene lugar la sustitución del Rey por el cargo del presidente de la República con un límite máximo de dos mandatos. Luego, las elecciones generales de 17 de noviembre de 1974, que coincidieron con el primer aniversario de los sucesos de la Universidad Politécnica, donde los diez años transcurridos desde las últimas elecciones de 1964 habían cambiado mucho la edad media del electorado y fueron acompañados por un notable crecimiento de la población urbana ${ }^{10}$, fueron claves para la democratización griega y la aprobación de la Constitución el 7 de junio de 1975, marcó el fin del proceso de la transición.

Es indudable que el momento en que se inicia la transición es la noche en la que el entonces Presidente Gizikis llamó a Karamanlís para entregarle la responsabilidad del poder. Pero, aunque según nuestra opinión la transición se acabó con la nueva constitución porque, a partir de este momento, el nuevo sistema poseía ya las características necesarias de una democracia parlamentaria, consideramos que las características políticas más importantes, que diferenciaron el nuevo sistema político de los anteriores, no fueron incorporadas en su totalidad hasta el término de los siguientes doce años, acabando con la reforma constitucional de 1986 que estableció un primer ministro extremadamente poderoso. Consideramos importante mencionar

\footnotetext{
${ }^{7}$ Sotiropoulos, Dimitri, “The authoritarian past and contemporary Greek democracy”, en South European Society and Politics, vol. 15, 3 (2010), pp. 449-465. DOI: http://dx.doi.org/10.1080/13608746.2010.513604.

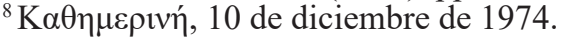

${ }^{9}$ Mavrogordatos, George, "El sistema griego de partidos”, en Revista de Estudios Políticos, 27 (1982), pp. 95-96.

${ }^{10}$ Macridis, Roy, "Elections and political modernization in Greece", en Penniman, Howard (ed.), Greece at the Polls: the national elections of 1974 and 1977, Washington, American Enterprise Institute for Public Policy Research, 1981, pp. 12-13.
} 
que en el discurso público griego el término metapolitefsi, que significa el paso de un sistema político a otro, es decir "transición”, se utiliza para referirse a toda la época que se inauguró en 1974 y cuyo fin es todavía indefinido.

De hecho, existen diferentes opiniones sobre el fin de este periodo. Por ejemplo, mientras Costas Simitis, primer ministro socialista entre 1996-2004, lo encuentra en el comienzo de la crisis y las elecciones de $2009^{11}$, Antonis Manitakis, profesor de Derecho Constitucional y ministro de Reforma Administrativa (2012-2013) considera que tuvo lugar en el 3 u 8 de mayo de 2010, el día que se puso en marcha el primer rescate de la troica ${ }^{12}$. Sin embargo, para el politólogo Elias Nikolakopoulos el fin de la Metapolitefsi como etapa no supera a los años noventa, cuando los principales actores de la transición se retiran de la escena política ${ }^{13}$ y Yiannis Voulgaris argumenta que su fin está en los años 1989-1990, por razones principalmente internacionales ${ }^{14}$. Juan José Linz y Alfred Stepan encuentran el fin del proceso de la transición en el referéndum de diciembre de 1974 porque a partir de este momento el gobierno era responsable frente al Parlamento ${ }^{15}$. Para el historiador Kostis Kornetis, la transición como proceso de cambio político acaba con las elecciones generales de noviembre de 1974, si bien hace una distinción entre la metapolitefsi como transición política y la metapolitefsi como etapa histórica ${ }^{16}$.

Es importante destacar que, como Richard Gunther, Nikiforos Diamandouros y HansJürgen Puhle han subrayado, existe una diferencia esencial entre transición y consolidación democrática. El primero acaba con el establecimiento de instituciones democráticas estables en Grecia y consideramos que termina con la aprobación de la Constitución el junio de 1975, teniendo en cuenta que las elecciones generales y el referéndum habían sido claves en el proceso pero como tal no fueron suficientes para marcar el fin de la transición. En segundo lugar, el proceso de la consolidación acaba cuando las instituciones democráticas no se niegan y no existe una amenaza capaz de derrocar al régimen democrático. Según los tres politólogos, la democracia en Grecia había resultado consolidada en 1977 o en 1981 y en ambos casos el crecimiento de la influencia política del PASOK se considera clave ${ }^{17}$. Nosotros consideramos la segunda fecha como fin de la consolidación democrática porque, en el ámbito de la praxis

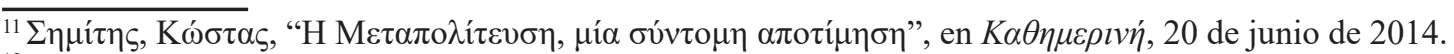

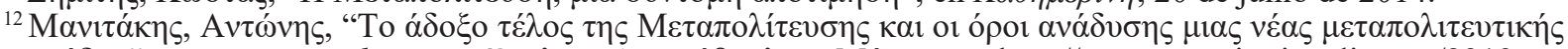

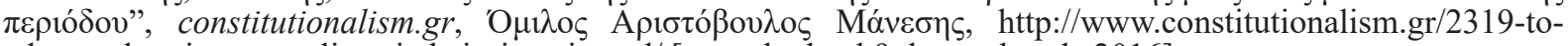
adoxo-telos-tis-metapoliteysis-kai-oi-oroi-anad/ [consultado el 9 de octubre de 2016].

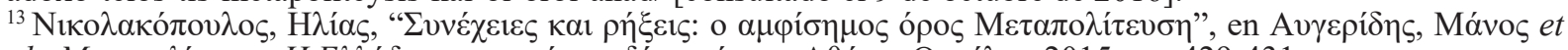

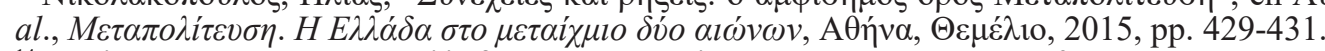

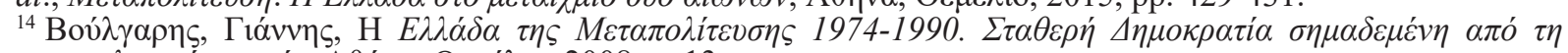

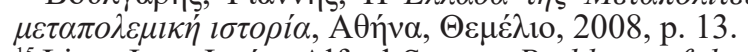

${ }^{15}$ Linz, Juan José y Alfred Stepan, Problems of democratic transition and consolidation, Baltimore, The Johns Hopkins University Press, 1996, p. 132.

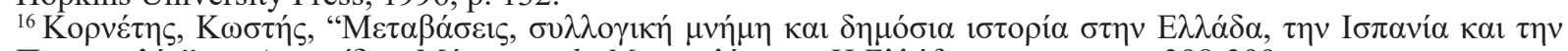

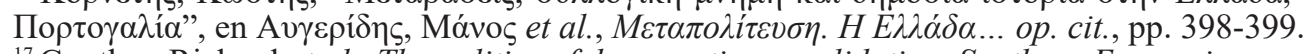

${ }^{17}$ Gunther, Richard et al., The politics of democratic consolidation. Southern Europe in comparative perspective, Baltimore y Londres, The Johns Hopkins University Press, 1995, pp. 1-32.
} 
política, los actores principales del sistema político habían aceptado las normas del antagonismo político dentro del marco democrático y constitucional.

El objetivo del presente trabajo es analizar los hechos políticos más significantes en la metapolitefsi no como transición sino como etapa histórica, esto es, la Tercera República Helénica, como oficialmente se conoce, y su impacto en el sistema político que nació tras el fracaso de la dictadura. Nuestra hipótesis es que en la transición griega a la democracia y en el sistema político consolidado existen tanto elementos de reforma del mismo, como de ruptura, principalmente en comparación con el sistema establecido tras el fin de la guerra civil. De hecho, analizando los procesos que hemos ilustrado en las líneas anteriores, nuestro objetivo es dilucidar cuáles de estos significaron ruptura y cuáles reforma. Por lo tanto, aquí consideramos que la transición hacia la democracia acaba en junio de 1975, con la aprobación de la nueva Constitución, y la consolidación en 1981. El estudio acabará en 1986, año en que el Partido Socialista realizó la revisión constitucional y momento en que, como veremos, fueron incorporados aquellos aspectos que indicaban que el sistema político de la metapolitefsi ya tenía su propia idiosincrasia política.

\section{El comienzo de la transición}

Al igual que en España el régimen franquista no cayó por la presión de una revolución sino solo tras la muerte de Francisco Franco, en Grecia el inicio de la transición tampoco fue únicamente un levantamiento de la población. La razón principal: la incapacidad de la Dictadura para tratar el problema de la invasión del ejército turco en Chipre, consecuencia de su intento de derrocar al presidente de la isla y el consecuente abandono del poder ${ }^{18}$. El 23 de julio de 1974, el entonces "presidente de la República", el general Gizikis, después de los sucesos en Chipre, llamó a los políticos más importantes del periodo anterior a 1967 con la finalidad de discutir una solución. En esta reunión, los políticos involucrados, entre ellos el primer ministro del Gobierno al que los coroneles habían derrocado siete años antes, dijeron al presidente que el ex primer ministro Konstantinos Karamanlís era la persona adecuada para gestionar el restablecimiento de la democracia ${ }^{19}$. En cuestión de horas, Karamanlís regresó a Atenas en el avión personal del presidente de Francia después de once años en el exilio.

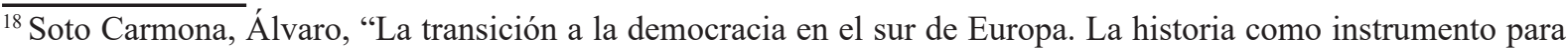
su comparación", en Estudios internacionales, Revista del Instituto de Estudios Internacionales de la Universidad de Chile, 162 (2009), p. 9.

${ }^{19}$ Diamandouros, Nikiforos, "Regime Change and the Prospects for Democracy in Greece: 1974-1983", en O'Donnell, Guillermo et al., Transitions from Authoritarian Rule. Southern Europe, Baltimore y Londres, The Johns Hopkins University Press, 1986, p. 158.
} 
Por lo tanto, fue el antiguo personal político el que ejerció la responsabilidad de restaurar, como entonces se decía, la democracia en Grecia. Karamanlís fue primer ministro ocho años, entre 1955 y 1963. Igualmente, muchos de los miembros de sus gabinetes de estos años fueron ministros en 1974, como por ejemplo Georgios Rallis, Evangelos Averoff-Tositsas y el primer presidente de la República elegido por el Parlamento Konstantinos Tsatsos. La razón por la cual los políticos conservadores y centristas fueron principalmente los que se encargaron de la restauración de la democracia es fácil de explicar. Y es que fueron los militares quienes negociaron las condiciones y, finalmente, les dejaron el poder a ellos. De hecho, los políticos más radicales fueron excluidos. Además, pese a que ellos recibirían con más facilidad el apoyo de EE.UU. y de la CEE, tan solo habían transcurrido siete años desde el golpe de los Coroneles. Así, en el momento que los dirigentes de la dictadura quisieron formar un gobierno civil, el personal político para hacerlo estuvo disponible, eso es, el primer ministro que fue sustituido en 1967 y los demás políticos del centro y de la derecha (sin los izquierdistas) estuvieron disponibles para negociar la formación del nuevo gobierno.

El primer gobierno que formó Karamanlís fue llamado el gobierno de la "Unidad Nacional”. Pero la izquierda no ocupó cargos y en él participaron solo los políticos que en 1967 estaban en los partidos de la derecha y del centro. Pero todos ellos compartían su oposición a la dictadura e incluso algunos de los miembros del nuevo Gobierno habían estado exiliados por mandato de los Coroneles. Además, el término que entonces se utilizó era "restablecimiento" de la democracia, referido al sistema anterior de la Dictadura. Indicativo es que la sección del archivo personal de Karamanlís, el cual contiene los documentos relativos a la época de la transición se titule "La restauración de la Democracia". Quedaba ahora que el líder conservador, que ganó las primeras elecciones democráticas de noviembre de 1974, demostrase su intención de romper con la herencia de los años 1949-1967 y no solo con la dictadura.

Un objetivo más de los que mencionamos anteriormente fue el de retomar las negociaciones para la incorporación a la Comunidad Económica Europea. Fue un proceso clave del periodo que estudiamos porque el primer ministro consideraba las instituciones comunitarias como garantía de la consolidación democrática ${ }^{20}$ y una forma de controlar la influencia de los Estados Unidos, que habían dominado la política griega durante casi tres décadas ${ }^{21}$. Pese a que empezaron con el tratado de 1961, que reconocía a Grecia como Estado asociado al Mercado Común y le daba así una ventaja sobre el resto de países en lo que constituye el primer intento de integración de un Estado a la CEE después de su fundación, esta fue pospuesta a causa del régimen autoritario de los coroneles. Así pues, la principal meta de la política exterior del nuevo gobierno, además de la pronta resolución del conflicto chipriota, fue la integración griega a la Comunidad Europea.

\footnotetext{
${ }^{20}$ Karamouzi, Eirini, "The Only Game in Town? EEC, Southern Europe and the Greek Crisis of the 1970s", en Rajak, Svetozar et al., The Balkans in the Cold War, Londres, Palgrave Macmillan, 2017, p. 221. DOI: 10.1057/9781-137-43903-1 10.

${ }^{21}$ Economides, Spyros, “The Relevance of «Europe» to Greek Foreign Policy”, en Featherstone, Kevin (ed.), Europe in Modern Greek History, Londres, Hurst \& Company, 2014, pp. 62-63.
} 
Este proceso, aunque en un primer momento acarreó problemas importantes como, por ejemplo, la solicitud de entrada por parte de España y Portugal, algo que había atemorizado al gobierno griego por el posible retraso en su proceso de incorporación, finalizó de manera positiva para Grecia tras la firma del tratado de adhesión el 28 de mayo de 1979, convirtiéndose en el décimo miembro de la CEE, a partir de 1 de enero de $1981^{22}$. Además, en este tema iba a desarrollarse una de las líneas principales del discurso político de PASOK, esto es, la crítica a la política del gobierno hacia la incorporación, rechazando los beneficios de esta, siendo así uno de los temas principales del antagonismo de gobierno y de la oposición principal, sobre todo a partir de 1977.

\section{El predominio de la política}

El gobierno formado tras el colapso de la dictadura no tenía, hasta la convocación de elecciones, la legitimidad que otorgaba ser un gobierno democrático elegido por el pueblo. Como los que permitieron la formación de un gobierno civil fueron los dirigentes militares, la tolerancia de las fuerzas armadas fue importante en los primeros meses de la transición. Pero, al mismo tiempo, las fuerzas armadas fueron humilladas por su incapacidad de defender Chipre y dejaron el poder de inmediato cuando les resultó imposible movilizarse contra el ejército turco ${ }^{23}$.

Los primeros meses después de la caída de la Dictadura, el nuevo gobierno siguió un camino hacia la democratización que, aunque no había resultado largo, sí había sido cuidadoso. Por ejemplo, el nuevo gobierno no desmovilizó al Jefe del Estado Mayor y otros militares de alto cargo hasta el 19 de agosto, casi un mes después de la formación de gobierno civil ${ }^{24}$. Aunque no había transcurrido mucho tiempo, Ioannidis había cambiado el Jefe del Estado Mayor el mismo día que derrocó al coronel Papadopoulos, es decir, el 28 de noviembre de $1973^{25}$ y el nuevo gobierno hizo los cambios en los altos cargos de las fuerzas armadas con mucha cautela y después de una reunión secreta donde se decidió reemplazar a los jefes de las fuerzas armadas ${ }^{26}$. De igual forma, el general Faedon Gizikis permaneció en el cargo superior del Estado hasta la convocatoria del referéndum sobre la monarquía. Karamanlís quiso la permanencia del general

\footnotetext{
${ }^{22}$ Para la historia de las negociaciones entre Grecia y la CEE véase el artículo de Fernández Soriano, Víctor, "Grecia, el socio díscolo. Las negociaciones de adhesión a las comunidades europeas, entre la euforia y la controversia (1976-1982)", en Circunstancia, 34 (2014). «http://www.ortegaygasset.edu/publicaciones/circunstancia/anoxii---n--34---mayo-2014/articulos/grecia--el-socio-discolo--las-negociaciones-de-adhesion-a-las-comunidadeseuropeas--entre-la-euforia-y-la-controversia--1976-1982-» [consultado el 6 de diciembre de 2016].

${ }^{23}$ Sotiropoulos, Dimitri, "The authoritarian past..." op. cit., pp. 449-450.

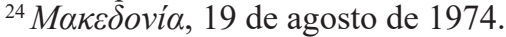

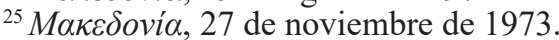

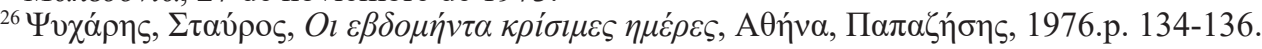


en la Presidencia de la República para no abrir el camino a la vuelta del Rey. Además, le resultó importante para controlar el ejército en esta fase de la transición ${ }^{27}$. Por ejemplo, en 1978, en la Comisión del Parlamento que investigaba los sucesos en Chipre, K. Karamanlís declaró que había apoyado al gobierno, subrayando que le había informado de la conspiración de treinta militares que quisieron detener al gobierno el otoño de $1974^{28}$.

Sin lugar a dudas, no le resultaría fácil al Ejército retomar el poder después de que sus militantes de altos cargos decidieran llamar a Karamanlís, siendo imposible seguir gobernando después de los sucesos de Chipre, tan poco tiempo después del golpe de Ioannidis contra Papadopoulos. Pero los primeros meses de la transición existía el peligro de la reacción de aquellos sectores militares que no querían la democratización del país. Buen ejemplo son las informaciones que llegaron al primer ministro el 11 de agosto que algunos oficiales intentarían derrocarle el mismo día ${ }^{29}$ y el caso de los 21 oficiales del Ejército que el gobierno arrestó en febrero de $1975^{30}$. De ellos, 14 fueron castigados por los jueces, lo que no impidió que en los años siguientes se produjesen algunas conspiraciones dentro de las Fuerzas Armadas; sin embargo, todas resultarían muy débiles para amenazar al Gobierno ${ }^{31}$. Aunque el hecho de que hubiera militares que quisieran restablecer el Ejército como factor importante de la política griega tuvo su importancia, realmente no puso en peligro el proceso democratizador y hasta 1975 hubo una relativamente importante limpieza de las fuerzas armadas de militares que apoyaron la dictadura, aunque no completa ${ }^{32}$. El gobierno de los Estados Unidos en 1976 no clasificaba como totalmente imposible el peligro de un golpe de Estado por sectores de las fuerzas armadas, pero Karamanlís había respondido que no creía que existiera una amenaza importante ${ }^{33}$. De todas formas, Konstantinos Karamanlís muchas noches dormía en distintos sitios, como por ejemplo en un barco, por razones de seguridad ${ }^{34}$ y el ministro de Gobernación del primer gobierno de la transición Georgios Rallis confirma, en sus memorias, que el gobierno no controlaba el ejercito los primeros días, por lo que el ministro de Orden Publico general Solon Gikas había sido clave para controlarlo ${ }^{35}$. Él poseía mucho prestigio entre los oficiales

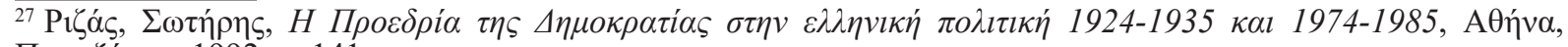

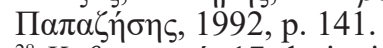

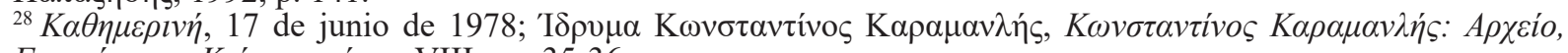

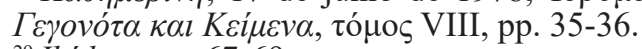

${ }^{29}$ Ibídem, pp. 67-69.

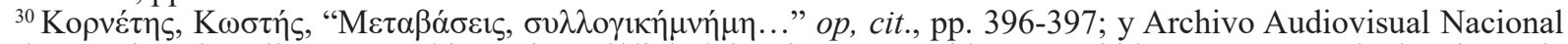
de Grecia, «http://mam.avarchive.gr/portal/digitalview.jsp?get_ac_id=1227\&thid=2904» [consultado el 19 de septiembre de 2016].

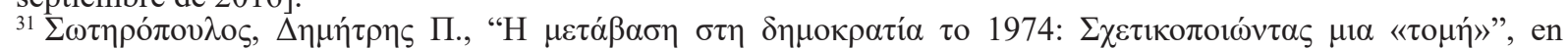

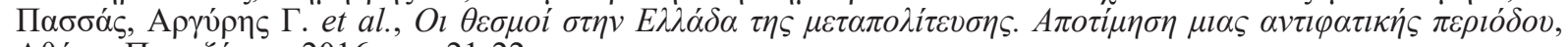
А $\theta \dot{v} v \alpha, \Pi \alpha \pi \alpha \zeta \eta ́ \sigma \eta s, 2016$, pp. 21-22.

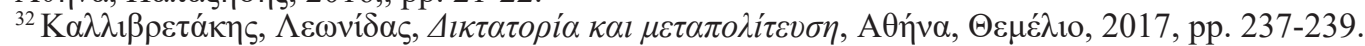

33 "Memorandum From A. Denis Clift of the National Security Council Staff to the President's Assistant for National Security Affairs (Scowcroft)", 1 de octubre de 1976. «https://history.state.gov/historicaldocuments/frus196976v30/d70» [consultado el 29 de septiembre de 2016]. La existencia de conspiraciones contra el gobierno de Karamanlís y la posible implicación del Rey en estas es un asunto que merece de investigación.

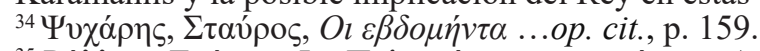

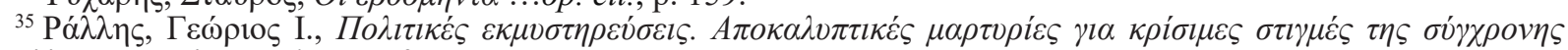

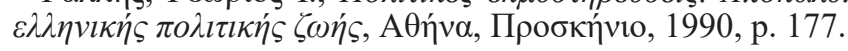


del ejército y junto con el Ministro de Defensa Evangelos Averoff fueron claves para el manejo del ejército ${ }^{36}$.

El 5 de noviembre de 1974, el fiscal levantó cargos de alta traición contra los militares que participaron en el golpe de Estado el 21 de abril de 1967. Hasta entonces, habían estado libres o bajo arresto domiciliario. La razón para la persecución fue el pleito contra los responsables de la Dictadura de la Unión de Abogados Demócratas ${ }^{37}$. Hasta enero de 1975 estuvieron libres e incluso el Gobierno había dicho a los golpistas que podrían irse del país ${ }^{38}$. Unos meses después, el 23 de agosto de 1975, los responsables del golpe de Estado fueron sentenciados a muerte, la cual fue convertida en cadena perpetua por parte del Gobierno, decisión que provocó la reacción de los partidos de la oposición ${ }^{39}$. Como el profesor de Derecho Constitucional de la Universidad de Atenas Nikos Alivizatos afirma, el juicio de los golpistas griegos era un hecho significante de la transición griega ya que los jueces, por primera vez en la historia del estado griego, tuvieron un papel importante en el proceso político ${ }^{40}$.

El sistema político implantado en 1974 fue gradualmente un sistema de dos partidos grandes como gobierno y oposición principal. Pero había dos diferencias esenciales con el periodo pre-dictatorial: la ausencia del Rey como Jefe de Estado y la legalización del Partido Comunista (KKE). El partido liderado por Konstantinos Karamanlis Nueva Democracia (ND) ganó las elecciones de 1974 con el 54,37\% de los votos y las de 1977 con el 41,84\%. El Partido Comunista se había dividido en dos sectores (1968): el KKE, que era pro-soviético, y el KKE Interior, que era el partido del eurocomunismo. En las primeras elecciones democráticas, estos partidos junto con el partido Unión de Izquierda Democrática (EDA) formaron la coalición electoral Izquierda Unida y obtuvieron el 9,5\% del voto popular, un resultado que reflejó la escasa influencia que tenía el comunismo.

La legalización del Partido Comunista era muy importante por el establecimiento de un régimen democrático ajeno al sistema parlamentario de la época de después de la guerra civil. El hecho era importante porque marcaba el fin del anticomunismo institucionalizado y oficial que inauguró el partido liberal de Eleftherios Venizelos en 1929, cuyo apogeo fue la prohibición del partido en 1936 por la dictadura de Ioannis Metaxas. Después de la Guerra Civil la represión del partido comunista había sido posible con unos estatutos especiales, conocidos como "medidas extraordinarias", desarrollados en paralelo con la Constitución, cuyo objetivo era la exclusión de los comunistas de la vida política y la represión social. Así, después de casi 45 años el

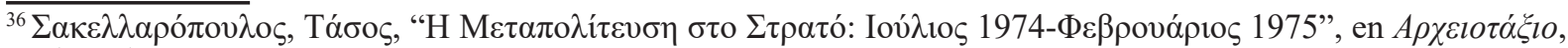
15 (2013), pp. 17-19.

${ }^{37} \mathrm{~K} \alpha \theta \eta \mu \varepsilon \rho v \eta \dot{,}, 6$ de noviembre de 1975.

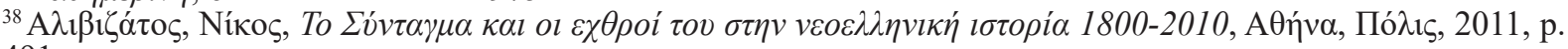
491

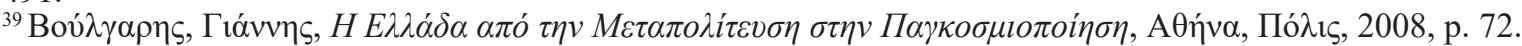

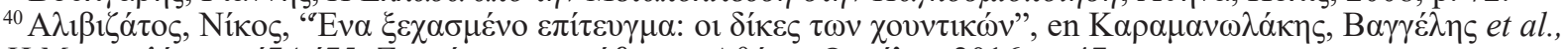

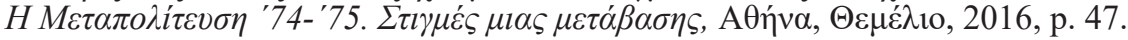


Partido Comunista tenía todo el derecho a existir, sin el peligro de que fuera suprimido por el Estado o por aquellas fuerzas que funcionaban bajo su tolerancia.

Por ejemplo, el crecimiento electoral de la EDA, la formación legalizada de los comunistas, en las elecciones de 1958, cuando había resultado el partido de la oposición principal, provocó la movilización de estas fuerzas y la creación del plan Periklis por militares de altos cargos y con la participación del futuro dictador Papadopoulos, que trataba de atenuar el crecimiento político de la izquierda, que los años próximos, provocaría una crisis política importante ${ }^{41}$ e incluso el asesinato del diputado de la EDA Grigoris Lambrakis en $1963^{42}$. Finalmente, un hecho significativo de la importancia que tuvo la legalización de este partido es que lo hiciera precisamente Konstantinos Karamanlís, líder del partido conservador y primer ministro durante 8 años, entre 1955-1963, en pleno contexto de la realidad de la Guerra Fría que entonces existía. Así, el viejo político que como persona había crecido cuando los comunistas se consideran enemigos del estado y había gobernado cuando tuvieron lugar los hechos anteriormente mencionados, en 1974 quiso ir un paso por delante y poner un fin en el dualismo institucional. Por su parte, la Comisión Central del Partido Comunista, tras el resultado de las primeras elecciones generales, a pesar de la crítica al gobierno por la forma en que realizaba la transición, declaró que el establecimiento de una "democracia verdadera" era responsabilidad de todas las fuerzas políticas ${ }^{43}$.

El otro gran actor de la política griega fue el Movimiento Socialista Panhelénico (PASOK), con Andreas Papandreou como líder. Destacado profesor de economía en Estados Unidos, había sido ministro durante el gobierno de Unión de Centro dirigido por su padre, Georgios Papandreou, entre 1964-1965, el cual había sido derrocado por el joven Rey Konstantinos en el verano de 1965. La razón principal fue el deseo del monarca de preservar el derecho real de nombrar el Ministro de Defensa, es decir, la Corona quiso mantener el control del Ejército. Andreas Papandreou fue acusado de ejercer el liderazgo en una organización secreta de oficiales militares izquierdistas, del ASPIDA, una acusación que, aunque jamás se demostró que resultara cierta, hizo que los sectores más radicales del Ejército no vieran con buenos ojos el gobierno del Centro y la política del hijo Papandreou ${ }^{44}$. Papandreou desarrolló el antiamericanismo y una identidad política que podemos situar a la izquierda de su padre y durante la Dictadura y en el exilio (1967-1974) fundó el PAK, el Movimiento Pan-heleno de Liberación. El PASOK pasó de ser el tercer partido del Parlamento a ser la oposición principal en las elecciones de 1977, relegando a los partidos centristas e izquierdistas a la tercera, cuarta y sexta posición. En 1981, con el 48.07\% de los votos, el PASOK formó su primer gobierno de la Metapolitepsi; un

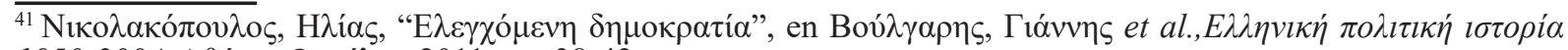

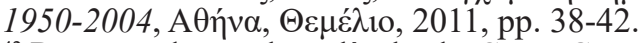

${ }^{42}$ Recomendamos la película de Costa-Gavras "Z", con Yves Montand, que trata la historia del asesinato de Lambrakis.

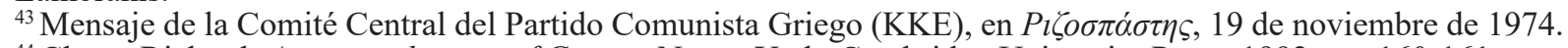

${ }^{44}$ Clogg, Richard, A concise history of Greece, Nueva York, Cambridge University Press, 1992, pp. 160-161.
} 
hecho que fue, sin duda, de gran importancia para la consolidación democrática ${ }^{45}$. Además, en el nuevo sistema político democrático, los partidos políticos se iban ganando gradualmente un papel importante dentro del proceso socio-político ${ }^{46}$. Con las elecciones de 1985 se confirmó que el PASOK y la ND se convertirían en los dos actores principales del sistema partidario, consolidando así el nuevo bipartidismo que había empezado en 1977, pues los dos partidos sumaban el $80 \%$ del voto popular.

La diferencia esencial radicaba en que los partidos radicales, especialmente el Partido Comunista y luego el PASOK, habían podido participar en la vida política sin restricciones, ya sean legales o ilegales. Después de 1977, el PASOK se consolidó como unos de los principales actores del sistema político, primero como oposición principal y luego como gobierno. El desarrollo de este partido ha sido clave para la consolidación democrática en primer lugar porque se caracterizaba como partido radical, y en segundo lugar, porque se oponía a las líneas principales de la política exterior del gobierno conservador, principalmente a la adhesión de Grecia a la CEE. Andreas Papandreou hablaba primero sobre la necesidad de convocar un referéndum sobre la permanencia en la CEE y luego sobre la re-negociación de las reglas de la adhesión. El PASOK se presentó como fuerza "anti-derechista" y el partido del "Cambio", y Papandreou realizó el juramento como primer ministro heleno bajo la observación del presidente de la República, Konstantinos Karamanlís, completando una pacífica alternancia en el poder. Por lo tanto, la subida pacifica de un partido con programa radical al poder, que cuestionaba las líneas principales de la política desarrollada por el partido conservador que había realizado la transición, fue un hecho significante para la consolidación de una democracia en la cual las fuerzas armadas no iban a tener el papel que jugaron antes de 1974.

\section{Jefe de Estado, Jefe de Gobierno y equilibrio de poder}

Cuando Konstantinos Karamanlís asumió el cargo de Presidente de Gobierno, volvió a poner en vigor la constitución de 1952, con la excepción de los artículos referidos a la monarquía, por lo que el General Gizikis permaneció como presidente de la República hasta la convocatoria de un referéndum. Esto significaba que el último Jefe de Estado del régimen autoritario sería reemplazado por el Rey o por un nuevo presidente, dependiente del resultado

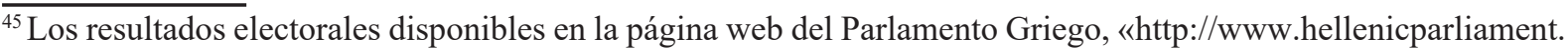
gr/Vouli-ton-Ellinon/To-Politevma/Ekloges/Eklogika-apotelesmata-New/» [consultado el 18 de abril de 2015]. ${ }^{46}$ Spourdalakis, Michalis y Chrisanthos Tassis, "Party Change in Greece and the Vanguard Role of PASOK", en Bosco, Anna y Leonardo Morlino, Party Change in Southern Europe, Londres y Nueva York, Routledge, 2007, pp. 160-161.
} 
de voto popular. El 8 de diciembre el $69,18 \%$ del voto popular fue a favor de la república constitucional, cerrando así un tema crucial para el futuro del país.

A lo largo de siglo xx, en diferentes momentos, hubo tensión entre el Rey como Jefe del Estado y de las fuerzas armadas y el primer ministro como jefe del poder ejecutivo. En realidad se trataba de una rivalidad sobre quién tendría la supremacía a la hora de decidir en los momentos críticos. El Rey y el primer ministro tenían aliados tanto dentro de las fuerzas armadas y del mundo político como en la propia sociedad. Primero fue el antagonismo entre el Rey Konstantinos I y el primer ministro Eleftherios Venizelos en el periodo 1915-1917 acerca de la participación de Grecia en la Primera Guerra Mundial, un intenso enfrentamiento que realmente tuvo características de guerra civil siendo conocida en la historiografía griega como “Cisma Nacional”. Durante casi veinte años, la tensión entre República y Monarquía se alternaba, provocando una enorme división social, golpes de Estado y hechos que quedaron marcados en la memoria colectiva ${ }^{47}$. En 1936 se estableció la dictadura de Metaxas, en la cual el Rey Georgios II funcionaba como factor de equilibrio en la política del dictador ${ }^{48}$. La Constitución de 1952 permitía al Rey actuar como mediador entre las diferentes fuerzas políticas y desempeñar un papel importante en la vida política ${ }^{49}$. Luego, la disputa entre el Rey Pavlos y el primer ministro Konstantinos Karamanlís sobre el intento del último para reformar la constitución, tuvo como consecuencia la dimisión del primer ministro. Por último, el Rey Konstantinos II, en julio de 1965, provocó la caída de primer ministro Georgios Papandreou, que, en consecuencia, sufrió una crisis política que abrió el camino a la dictadura de los Coroneles. Parece, pues, que el equilibrio existente entre los dos cargos nublaba los límites de poder entre ellos.

El referéndum de 1974 abolió la Monarquía. En su lugar, la nueva constitución, aprobada por el Parlamento el día 7 de junio 1975, ponía al presidente de la República, elegido por el Parlamento cada cinco años, con derecho a re-elección una vez. Sin embargo, no era la primera vez en la historia griega que se convocaba un referéndum sobre este tema y hubo convocatorias en 1920, 1924, 1935, 1946 y en 1973 (la última de la dictadura) pero ninguna se caracterizaba por su validez. En 1974, los partidos políticos no negaron el resultado y el primer ministro no comunicó su opinión en público, adoptando una posición neutral. Hasta la reforma de 1986, el presidente tenía unos poderes importantes. Pero para la elección del presidente era necesario conseguir los votos de dos tercios del Parlamento, esto es, 200 votos ${ }^{50}$. Por lo tanto, quedaba en los próximos años para ilustrar si habría una crisis entre el Jefe de Estado y el Jefe de Gobierno.

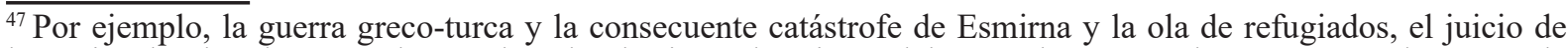
los Seis, el golpe de General Pángalos, de Plastiras, el régimen del general Metaxas, la "apostasía” de 1965 y la dictadura de los Coroneles.

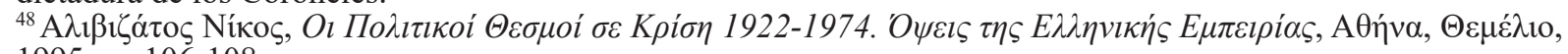
1995 pp. 106-108.

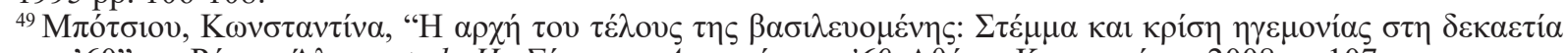

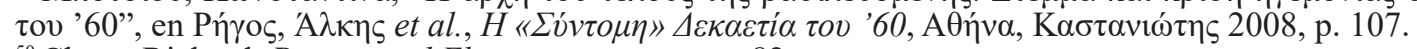

${ }^{50}$ Clogg, Richard, Parties and Elections... op. cit., p 82.
} 
La constitución de 1975 establecía una república parlamentaria, con el poder ejecutivo repartido entre el presidente de la República y el Gobierno (artículo 26) ${ }^{51}$. Pero la cuestión esencial no radicaba en la división del poder ejecutivo como tal, sino en qué poderes ejecutarían cada uno. Sin embargo, el presidente de la República tenía la obligación de nombrar como presidente de gobierno al líder del partido con la mayoría parlamentaria absoluta o de la concesión de las otras fuerzas parlamentarias. El presidente de la República era el jefe de las fuerzas armadas, pero su dirección era claramente una responsabilidad gubernamental (artículo 45).

El presidente de la República se otorgaba con unos poderes significativos que le permitirían, si lo hubiese querido, intervenir en la vida política y asumir la iniciativa sin el visto bueno del Gobierno. Según el artículo 35, todos los decretos presidenciales deberían ser acompañados de la firma del primer ministro o del ministro responsable. Pero en el mismo artículo se reconocían determinadas excepciones en las cuales el presidente podía poner en marcha algunos decretos sin la firma del Gobierno. El presidente tenía el derecho de llamar la junta de ministros y el Consejo de la Democracia. En este participaban el presidente, los ex presidentes de la República y del Gobierno, el presidente del Parlamento, el líder de la oposición principal y los expresidentes del Gobierno. Quedaban excluidos los que habían ocupado la jefatura dle Estado o del GObierno de manera no democrática. Este consejo lo podía convocar en los momentos que considerara críticos para la nación (artículo 39). Si en la reunión de este último se demostraba que el conjunto del Parlamento no concordaba con el deseo social, el presidente tenía el derecho de disolverlo y convocar nuevas elecciones (artículos 38 y 41). Sin embargo, es obvio que este artículo otorgaba al presidente la posibilidad de intervenir en la vida política sino estaba de acuerdo con la política del Gobierno, en la lógica que el presidente de la República era la última garantía de estabilidad.

Además, el Jefe del Estado podía convocar referéndums sin el visto bueno del primer ministro, eligiendo él la pregunta ${ }^{52}$, y también podía dirigirse al pueblo en momentos importantes (artículo 44). La constitución fue aprobada por el Parlamento el día 7 de junio de 1975, tan solo con los votos del partido conservador, sobre todo porque la oposición criticaba los amplios poderes concedidos al presidente de la República ${ }^{53}$. En realidad, la Constitución no establecería un sistema presidencialista, pero sí la figura de un presidente que tenía la capacidad de asumir un importante papel dentro de la vida política. Por lo tanto, el equilibrio de poderes que la nueva Constitución establecía estaba prácticamente indefinido, especialmente desde el momento en que no se clarificaba cuándo el presidente iba a ejercer los derechos que se le reconocían. Es importante decir que el presidente era, y es hasta hoy, elegido por el Parlamento

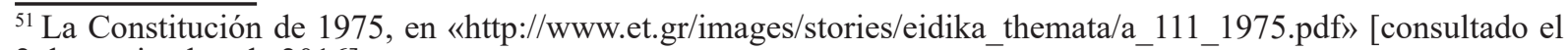
2 de septiembre de 2016].

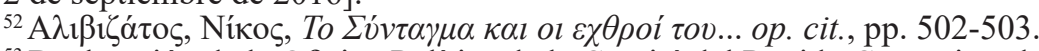

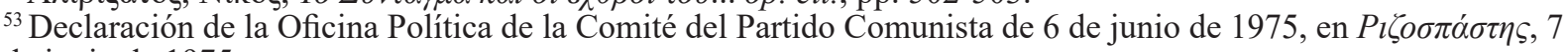
de junio de 1975 .
} 
y no directamente por el pueblo, con la necesidad de una mayoría de votos amplia. Y es que, al ser Grecia desde 1974 una República Constitucional representativa, los votos de la mayoría del Parlamento son suficientes para legitimar la elección de una persona en el alto cargo del Estado. Pero una decisión que implicaría su intervención en la política del Gobierno podría haber provocado una crisis política. Así, solo el Gobierno puede legitimar su política directamente por el voto popular. Además, como es necesaria una mayoría amplia, sería difícil la elección de un presidente no favorable al Gobierno o, mejor dicho, la elección de un candidato que el Gobierno no quisiera poner en el cargo. Pero con la alternación de dos los partidos antagónicos en el poder, característica de los sistemas bipartidistas, cabría la posibilidad de que un partido que había votado en contra del Presidente en el cargo ganase las elecciones. Esto es el caso griego en 1981.

Durante en los últimos años de la década de los setenta se tenía la extendida creencia de que Karamanlís iba a moverse de la Presidencia del Gobierno a la Presidencia de la República, algo que sin duda él no refutaba, llegando a decir en su discurso para ratificar la Constitución que la oposición debería estar contenta en el caso de que él asumiese la presidencia ${ }^{54}$. Como en 1981 presidente de la República era Konstantinos Karamanlís, arquitecto de la política europea de Grecia, y primer ministro Andreas Papandreou, que amenazaba la política de Karamanlís, la cuestión entonces era qué haría Karamanlís si Papandreou intentara cambiar el camino europeo del país. Aunque finalmente no hubo una crisis entre los dos políticos, Karamanlís había subrayado en 1982 que una postura implacable del primer ministro socialista hubiera podido provocar la ruptura entre ellos ${ }^{55}$.

El 15 de mayo de 1980 Karamanlís asumió el cargo de presidente de la República. El 1 de enero de 1981 Grecia ya es miembro de pleno derecho de la CEE, una de las metas principales del viejo político conservador. En octubre del mismo año, el PASOK ganó las elecciones generales y Andreas Papandreou fue nombrado primer ministro, el primer dirigente del gobierno noconservador desde 1965. Papandreou tenía una retórica muy hostil hacia la CEE, amenazando con la convocatoria de un referéndum. Así, podría provocar una crisis entre el Gobierno y el presidente de la República en el caso de que los socialistas pusieran en peligro la participación del país en la CEE. Sin embargo, aunque el líder socialista amenazaba la participación de Grecia en la CEE, se demostró que lo hizo más por razones electorales, desde el momento en que aceptó realmente a la OTAN como garantía de la seguridad griega y declaraba en sus reuniones con oficiales extranjeros que no trataría de sacar a Grecia del mundo occidental, como lo hizo durante su visita a Londres antes de asumir el poder ${ }^{56}$, al tiempo que François Mitterrand había asegurado a Margaret Thatcher que el líder socialista griego no intentaría retirar a Grecia de las

\footnotetext{
$\overline{{ }^{54} K \alpha \theta \eta \mu \varepsilon \rho \imath v \eta ́}, 8$ de junio de 1975.

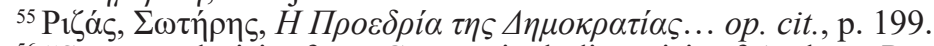

56 "Sponsored visits from Greece, including visit of Andreas Papandreou, Leader of the Opposition, November 1980". National Archives, Foreign Commonwealth Office, FCO 9/2981.
} 
instituciones comunitarias ${ }^{57}$. Igualmente, el nuevo primer ministro admitió ante el presidente de la República que realmente no deseaba convocar un referéndum, que prácticamente no tenía el poder de hacerlo, sino que la amenaza era un instrumento de negociación con la $\mathrm{CEE}^{58}$.

Pero la sola intención del gobierno socialista de convocar un referéndum ya era algo capaz de provocar una crisis entre el presidente y el Gobierno, en tanto que el primero podía anunciar un referéndum sin el visto bueno del segundo, pero al contrario no era posible. Así, aunque hasta la reforma de 1986 no se produjo ninguna crisis entre el presidente y el primer ministro a causa de los poderes del primero, en el nuevo sistema político la presidencia sí podía funcionar como obstáculo a los deseos gubernamentales. Sin embargo, hubo dos elementos clave a la hora de que no estallase una crisis institucional: primero, la propia personalidad de Karamanlís que, como actor principal de la Transición, no quería iniciar una tendencia de oposición entre Jefatura de Estado y Jefatura de Gobierno; y, segundo, el hecho de que Papandreou había manifestado, al menos en reuniones privadas, que aceptaría los objetivos de la política exterior de Karamanlís como hechos consumados.

Además, aunque las relaciones entre los dos políticos habían sido realmente buenas, como muestra la declaración de Papandreou en 1982 en la que afirmaba que Karamanlís era un buen presidente en tanto que el modo en que ejercía sus responsabilidades favorecía la consolidación democrática ${ }^{59}$, podemos decir que el gran porcentaje por el que ganó el PASOK en las elecciones de 1981 sorprendió a Karamanlís y, la escasa mayoría que asumió en el Parlamento Karamanlís en su elección como presidente en 1980 dio una ventaja de legitimación democrática a Papandreou frente a Karamanlís ${ }^{60}$. Pero, aunque esto es correcto, no significa que el presidente no pudiera ejercer sus derechos constitucionales si decidía hacerlo por alguna razón.

Aunque Papandreou había asegurado que iba a proponer la re-elección de Karamanlís, poco antes del fin de su mandato en 1985, anunció que su partido apoyaría a otro candidato y que después de las próximas elecciones generales revisaría la Constitución para atenuar los poderes del presidente ${ }^{61}$. Esto provocó la reacción de Karamanlís, que renunció a su cargo. Además, la votación de nuevo presidente resultó escandalosa. Sin embargo, aunque las razones que llevaron al líder socialista a elegir a otro candidato y proceder a la revisión de la Constitución son variadas, deberíamos analizar los equilibrios existentes dentro de su propio partido, los objetivos electorales y su ideología. A pesar de que su política podía provocar una crisis política importante, finalmente la normalidad institucional no fue negada. El nuevo presidente empezó su mandato y, después de cinco años durante los cuales se produjo la mayor crisis política

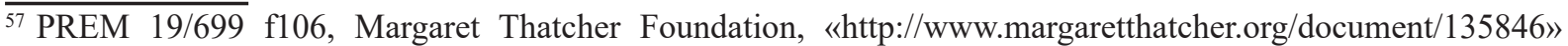
[consultado el 18 de diciembre de 2016].

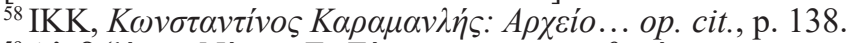

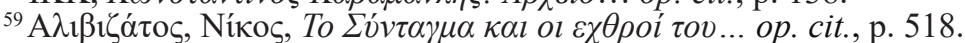

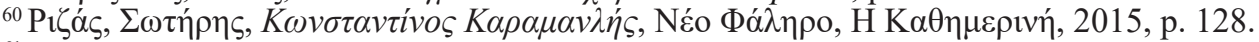

${ }^{61}$ El gobierno propuso como candidato Xristos Sartzetakis, que fue el interrogador del asesinato de Grigoris Lambrakis en 1963. Sin embargo, una candidatura con mucho simbolismo dentro de la izquierda.
} 
después de 1974, su legislatura acabó en 1990 y Karamanlís asumió el cargo por segunda vez, sin los votos del partido socialista.

El 6 de marzo de 1986, el Gobierno revisó la Constitución de 1975. El epicentro de dicha revisión fueron los artículos referentes a la Presidencia de la República, esto es, el establecimiento de un sistema en el cual el poder ejecutivo quedara, principalmente, bajo responsabilidad del primer ministro y del Gobierno. El artículo 26 no fue reformado, por lo que el poder ejecutivo continuó estando compartido entre el presidente de la República y el Gobierno. A pesar de esto, todos los artículos que otorgaban poderes al presidente de la República fueron revisados o eliminados. Más bien, perdió su derecho de convocar referéndums, competencia que fue transferida al Gobierno. De igual forma, el artículo 39 también fue eliminado, aboliendo así el Consejo de la Democracia, un instrumento que permitía al presidente de la República renunciar al Gobierno y convocar nuevas elecciones (artículo 41). Ahora, desaparecía este derecho para el presidente y, solo si el Gobierno perdía la confianza del Parlamento y si el propio Gobierno pedía la disolución del Parlamento, el Presidente estaaba obligado a convocar elecciones.

Resumiendo, la reforma constitucional de 1986 estableció un claro e institucionalizado equilibrio entre el Jefe del Estado y el primer ministro. Con el establecimiento de un sistema con un primer ministro muy poderoso y un presidente con responsabilidades más típicas que esenciales realmente, el predominio del primer ministro ante el presidente de la República era innegable. Aunque la Nueva Democracia eligió la abstención del voto de ratificación, lo mismo que hicieron los partidos de la oposición en 1975. El líder del principal partido de la oposición, Konstantinos Mitsotakis, declaró en el Parlamento que realmente era la primera vez que la revisión de la Constitución se hacía a través del proceso que la misma estipulaba ${ }^{62}$. Por lo tanto, una de las características más importantes de la Metapolitefsi, es decir, la existencia de un primer ministro poderoso que predomina sobre el presidente de la República, fue establecida por el Parlamento. Aunque existían críticas importantes por la creación de una poderosa mayoría sin el establecimiento de ninguna institución que pudiera funcionar como contrapeso para garantizar el equilibrio que garantizase una democracia real ${ }^{63}$, y en 1975 Karamanlís argumentó que, como el Jefe de Estado era realmente el regulador del sistema gubernamental, era inevitable la dotación de poderes que le permitieran ejercer sus responsabilices cuando fuera necesario ${ }^{64}$. En la realidad, con la reforma de 1986 el Jefe de Estado solo tiene poderes ceremoniales y el primer ministro tiene en sus manos muchos poderes sin la existencia de un balance quizás necesario. Sin embargo, aunque estas críticas eran importantes, la falta de un Jefe de Estado con poderes era, a nivel político, un hecho significante, sobre todo porque, en nuestra opinión, marcó una ruptura con la división del poder ejecutivo durante el siglo $\mathrm{xx}$, sea cuales fueran las razones políticas que llevaron el gobierno socialista a hacerlo, sobre todo su intento de ampliar el base electoral hacia la izquierda.

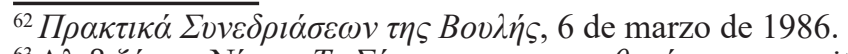

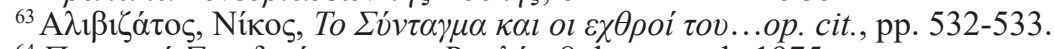

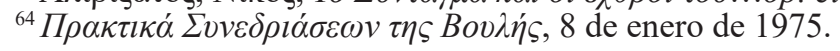


4. Conclusiones: ¿continuidad o ruptura?

La transición griega fue realmente una "reforma rupturista". Es decir, en el nuevo sistema coexistían tanto elementos de continuidad que fueron reformados en el nuevo sistema, como de ruptura. Era reforma porque quienes llevaron a cabo la transición primero y luego la consolidación de la democracia, habían obtenido su experiencia política en la época posterior a la guerra civil e incluso durante esta. Los principales políticos que formaron el gobierno de Unidad Nacional de 1974 fueron los mismos que la oposición culpaba de ser los responsables de la represión política durante las décadas cincuenta y sesenta. De igual forma, en los partidos de la oposición también existían elementos de continuidad. Por ejemplo, el líder del PASOK había iniciado su trayectoria política en el sistema anterior. Aunque el líder del partido intentó romper sus lealtades políticas con el partido de su padre, especialmente a nivel de discurso político, tanto la experiencia de los miembros del partido, como su base electoral, ponían de manifiesto una fuerte relación con la Unión de Centro ${ }^{65}$. El periódico del partido socialista Eksormisi, después del resultado del referéndum, hizo un paralelismo muy interesante entre Georgios Papandreou, líder de UUCC y su hijo Andreas Papandreou y líder del PASOK. En su portada publicó una foto del padre con su lema tras su derrocamiento por el Rey el julio de 1965 "la democracia vencerá...", poniendo a la derecha de esta la foto del hijo en 1974 el día de la abolición de la Monarquía con la frase “... la democracia ha ganado" Gerorgios Papandreou se presentaba como el sucesor de su padre en la lucha contra las fuerzas antidemocráticas.

Luego, el término utilizado era "restauración", que prácticamente significa continuidad con el sistema derrocado en 1967. Esta fuerte relación con el pasado se explica, como ya hemos mencionado, en el hecho de que, al contrario de España y Portugal donde las dictaduras duraron alrededor de cuatro décadas, Grecia salió de una dictadura de corta duración, siete años. Como no había pasado mucho tiempo desde el golpe de Estado de 1967, sí que existía un sistema político democrático (constitucional) reciente que los políticos del pasado podrían reclamar como la normalidad institucional que había sido derrocada. Es por eso que se ha utilizado el término "restauración" para referirse a la transición democrática griega. Pero, sin embargo, el cambio producido en junio de 1974 iba a ser algo mucho más profundo que un simple "cambio de guardia", como Andreas Papandreou decía que era el gobierno dirigido por Karamanlís ${ }^{67}$.

Además, el hecho de que el nuevo gobierno eligiera no enfrentarse contra los militares, sino que escogiera un cuidadoso camino que llevara a la justicia tan solo a los golpistas y unos

\footnotetext{
${ }^{65} \mathrm{Ni \kappa o \lambda \alpha \kappa ó \pi ov \lambda os,} \mathrm{Н \lambda í \alpha \varsigma ,} \mathrm{Е \kappa \lambda o \gamma \omega ́v} \mathrm{Па́ \theta \eta ,} \Delta \mathrm{O} \Lambda, 2012$, pp. 162-163.

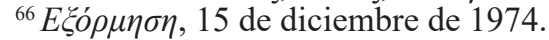

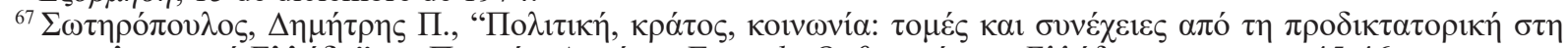

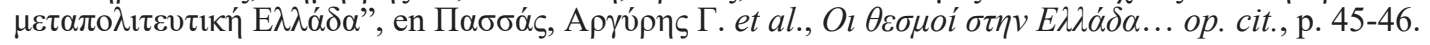


pocos responsables de la sangrienta represión de noviembre de 1973, ilustra la preferencia por una "ruptura gradual". Por añadidura, el Parlamento elegido en las primeras elecciones tras el fin de la Dictadura, el cual elaboró la nueva constitución, no tuvo poder constituyente sino poder de revisión. Es decir, el poder de revisar la Constitución si bien no solo revisó la Constitución de 1952, sino que fue más allá y llegó a cambiar la propia forma de Estado. Por tanto, el sistema constitucional de 1952, aunque democrático, excluía de la vida política a los comunistas, con lo que en realidad era un sistema con límites democráticos, tal y como pusieron de manifiesto, por ejemplo, las elecciones de 1961 que Georgios Papandreou consideró producto de la violencia y manipulación, aunque lo hizo cuando se dio cuenta de que esto afectaba a su partido, y no solo a las izquierdas. Por último, la policía continuó siendo un elemento de represión dinámica y, en la práctica, las divisiones sociales del pasado no fueron eliminadas o directamente superadas ${ }^{68}$.

Pero, al mismo tiempo, era ruptura. Primero fue la abolición de la Monarquía como tal, un hecho importantísimo que diferenció claramente la forma del Estado, siendo además la República aceptada también por el partido conservador. El nuevo sistema político incluyó a los comunistas y se eliminaron las "medidas extraordinarias" como forma legal de represión de la izquierda. De hecho, después de su llegada a Atenas, Konstantinos Karamanlís fundó el partido conservador Nueva Democracia, un nombre indicativo de su intento de romper con las lealtades del pasado, a nivel simbólico, aparte de su relación ideológica con el espacio político conservador de la época anterior ${ }^{69}$. Además, cuando el PASOK ganó las elecciones en 1981 con un programa radical que negaba las líneas principales del gobierno conservador, sobre todo la política hacia la CEE, pese a las amenazas de retirada o de convocatoria de un referéndum, el proceso democrático no fue negado por ningún partido político.

Sin embargo, Karamanlís ha sido una figura clave por la rápida y exitosa transición democrática. Igualmente, la política de adhesión a la CEE fue principalmente un deseo personal con el que el partido conservador se identificó. Por lo tanto, la aceptación del camino europeo por parte del partido de PASOK, prácticamente, como hemos citado, antes de 1981 pero oficialmente en $1988^{70}$, hizo que el objetivo principal del partido conservador que provocó la intensa oposición de PASOK, se convirtió en política innegable de los dos partidos que se alternaban el poder. Finalmente, aunque el líder conservador y su predecesor como presidente de la República no utilizaron los poderes que la Constitución les confería, podemos decir que la existencia de un primer ministro más poderoso que el Jefe de Estado es una de las características más importantes del sistema político griego del último cuarto de siglo xx.

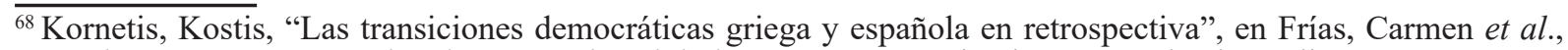
Reevaluaciones. Historias locales y miradas globales, Zaragoza, Institución Fernando el Católico, 2011, pp. 195196.

${ }^{69}$ Pappas, Takis y Elias Dinas, "From Opposition to Power: Greek Conservatism Reinvented”, en Bosco, Anna y Leonardo Morlino, Party Change in Southern Europe... op. cit., p. 141.

${ }^{70}$ Sotiropoulos, Dimitri, Populism and Bureaucracy. The Case of Greece under PASOK, 1981-1989, Indiana, University of Norte Dame Press, 1996, p. 68.
} 